\title{
What Is The Impact Of Job Burnout Antecedents On Georgia Nursing Home Administrators?
}

Dr. Felicia L. Wilson, St. Leo University, USA

\begin{abstract}
Retaining effective and qualified nursing home administrators is becoming a daunting task. With the increase of elderly people in America, the nursing home industry is being forced to address the leadership crisis in the industry. Participants in the study were licensed nursing home administrators $(N=363)$ who are employed in the state of Georgia. 141 completed surveys were returned for a response rate of 38\%. The purpose of the study was to investigate the impact of job burnout antecedents: workload, control, rewards, community, fairness, and values on Georgia nursing home administrators?
\end{abstract}

Keywords: Job Burnout; Workload; Control; Rewards; Community; Fairness and Nursing Home Administrators

\section{INTRODUCTION}

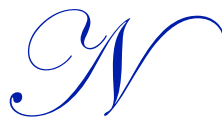

umerous studies have found that it is of great importance for management to understand the trials of employees and work towards providing a safe and encouraging environment to maintain happy and productive employees. Leading the job burnout research explosion, Maslach, Shaufeli and Leiter (2001) found a direct association between job satisfaction, organizational commitment and turnover. Another study conducted by Cordes and Dougherty (1993) also found a direct association between job burnout and low levels of job satisfaction. Parry-Jones, Grant, McGrath, Caldock, Ramcharan, \& Robinson (1998) reported that occupational stress has an adverse impact on health and social work professions, as evidenced by high levels of reported job stress. Despite this, human service workers continue to work in stressful environment. This level of job dedication can be linked to the foundation of caring and perseverance of the human services profession.

This research project focuses on exploring the six domains of the job environment: workload, control, reward, community, fairness, and values. Workload, control, reward, community, fairness, and values are antecedents of job burnout. According to Angerer (2003), Maslach created this new theoretical framework, which includes workload, control, reward, community, fairness, and values domains, to integrate individual and situational factors. When there is a mismatch within any domain, an employee has a greater chance of experiencing job burnout. Workload, control, reward, community, fairness, and values are directly linked to job stress and satisfaction.

The increase of elders in America has led to an overwhelming interest in nursing homes. The nursing home industry cares for over 1.8 billion people per year (Cavanaugh \& Blanchard-Fields, 2002). It is imperative that skilled, seasoned and effective leaders are retained to manage the complex nursing home environment. In addition to retaining seasoned leaders, effective and proven policies must be implemented to ensure the safety and well being of residents and staff. The turnover of staff and the quality of nursing home environments are related to job stress and job burnout. These factors, job stress and job burnout, have been studied in a variety of professions since the late '70s. The research question for this study is: To what extent does each independent variable (workload, control, rewards, community, fairness, and values) predict job burnout for the nursing home administrator? 


\section{BODY}

\section{The Antecedents of Job Burnout}

Maslach et al. (2001) developed a framework, coined job person fit to better understand job burnout. Angerer (2003) reported that the new theoretical framework of job burnout integrated both individual and situational factors. The new integration allows for a deeper understanding of job burnout and the employee. The six domains of job burnout are workload, control, rewards, community, fairness, and values. According to Maslach et al., burnout occurs when there is a mismatch between people and their work environment in one or all of these areas. The new framework of job burnout organizes the major organizational antecedents of burnout.

\section{JOB BURNOUT AND WORKLOAD}

The historical theoretical framework on job burnout separated the individual and situational factors versus integrating the two concepts. Maslach et al. (2001) recognized the historical separation as limiting the understanding of job burnout and created a new model that integrates the person and environment. The new integration presents a holistic understanding of job burnout. Specifically, researchers can now understand how workload impacts the person and their job. The definition of workload mismatch is "an excessive workload, through the simple formula that too many demands exhaust an individual's energy to the extent that recovery becomes impossible" (Maslach et al., p. 414). Workload mismatch is an antecedent of job burnout. When an individual has exceeded their ability to effectively manage job tasks because they are too numerous, the individual will become overextended and exhausted.

Eft-Russ (2001) conducted an exhaustive literature review and found that a leading human resource journal had not published any articles on workload. However, in the field of psychology, workload and its impact on job burnout has received focused attention. Workload has been shown to have a direct negative relationship with job satisfaction for new employees (Eft-Russ). According to Greenglass, Burke, and Moore (2003), burnout occurs from excessive workload and stress. Burnout happens when the employee experiences chronic imbalance in job demands and resources. So, for administrators who are new to the industry, workload would be a key factor in their retention. It is therefore important to make sure that administrators receive extensive training and continuous support to balance the demands of this complex environment.

Direct care nursing home employees have long been the focus of job burnout research. However, executive management has not been the focus of research to understand how workload impacts the nursing home administrator. This is unfortunate as the well being of the organization's leader is of great importance. Crampton Hodge, Mishra and Price (1995) reported that managers who are exposed to too much stress as a result of excessive workload are unable to concentrate and perform efficiently because their attention is spread across multiple areas. The nursing home administrator is responsible for the overall management of the facility. Not only are they legally responsible, but often times, they become emotionally attached to the organization's employees, residents and families. The inability to perform efficiently secondary to too many demands places the organization at an increased risk for substantial problems.

Templeton and Satcher (2007) conducted a study on job burnout among rehabilitation counselors. This research study revealed that rehab counselors often expressed excessive workload issues in relation to caseload size, stating that they were responsible for too many clients. The study involved 170 participants who completed the Maslach Burnout Inventory-Human Services Survey. The caseload for the counselors ranged from 40 to 500 . Overall, the counselors exhibited moderate emotional exhaustion, low depersonalization and high personal achievement. The results prove that with a supportive management team and effective policies and procedures, employees will maintain a positive attitude about their job in the midst of a complex and stressful environment.

Cherniss (1980) reported that professionals who work in a helping environment often have large caseloads and are more likely to have negative attitudes towards their job. Although rehab workers are in a different population than that of this study, nursing home administrators also have an extensive caseload, which could lead to a negative attitude towards their position. 
After an exhaustive literature review on job burnout, it has been clearly defined that workload is an antecedent to job burnout. What cannot be determined is how workload impacts the nursing home administrator. One could make the assumption that because excessive workload impacts other professionals negatively the same would be true for nursing home administrators. But, without empirical research to prove the impact of workload on this specific population, such a statement is pure speculation.

\section{JOB BURNOUT AND CONTROL}

Employees who have a sense of control over their work have a greater sense of ownership and feel empowered to do their jobs. When an employee experiences high demands for productivity with low control over how the work is accomplished, the employee begins to feel stressed and exhibit signs of cynicism (Angerer, 2003). A mismatch in control occurs when an employee feels they do not have the necessary resources and authority to effectively pursue their work (Maslach et al., 2001). This particular lack of control can be extremely distressing for individuals who are deeply connected to their work. Often times, such an individual feels that their work is a direct extension of themselves. When the work does not meet the individual's standards secondary to a lack of control, the cycle of burnout begins.

Khodyakov (2007) stated that organizational control is understood as "a regulatory process by which elements of a system are made more predictable through the establishment of standards in pursuit of some desired objective or state" (p. 3). The purpose of organizational control is to ensure that operations run smoothly and to foster a sense of cooperation between management and employees (Khodyakov). However, this type of organizational control limits the employee's creativity and ability to make independent decisions. In addition to limiting creativity, another disadvantage to organizational control is reducing trust between the employee and the organization. When someone is trusted, they have the ability to make decisions and have control to some extent over their job. Organizations that choose to limit control also limit the possibility of creating a trusting environment.

The ability to have control in one's work environment produces a greater sense of personal accomplishment and reduces workplace stress. A sense of autonomy and control in dealing with job responsibilities and tasks leads to increased performance and job satisfaction among employees (Tai, 2007). The definition of job autonomy/control includes the extent to which a job allows discretion, freedom, and independence to schedule work, and allows employees to select how the job will be completed (Tai). This type of autonomy cannot happen in a micromanaged environment where the organization sets the rules for each task (Khodyakov, 2007). Employees are more satisfied when they have some input into how their jobs are completed. The possibility of exhaustion, depersonalization, and reduced efficacy are greatly minimized when an employee has job autonomy and the ability to self-direct job responsibilities.

\section{JOB BURNOUT AND REWARD}

Intrinsic and extrinsic rewards are key domains in the area of job burnout. Research studies have shown that an established reward system will bolster employees' attitudes about their work and leads to increased job satisfaction (Angerer, 2003). However, when an employee does not receive extrinsic rewards, they may begin to feel that they are incapable of effectively doing their job, which is in essence a feeling of reduced efficacy. To combat reduced efficacy, an organization must integrate a reward system that recognizes excellence. Maslach et al. (2001) stated that a reward mismatch "involves a lack of appropriate rewards for the work people do" (p. 414). The aforementioned reward system focused on extrinsic rewards. These awards come in the form of money, benefits or other social recognition for a job well done. Templeton and Satcher (2007) reported that employees generally do not exhibit signs of job burnout when they receive positive recognition from supervisors.

Intrinsic rewards happen when individuals feel good about the work that they accomplish. Travis (2006) stated that intrinsic job satisfaction comes from the individual's gratification with the work itself. Furthermore, intrinsic motivation has been linked to persistence in tasks, expended effort and dedication to excellence (Travis). The ability to feel good about one's job and accomplishments is also connected to personal responsibility. When employees feel personally responsible for a task or job function, they tend to be protective, caring, and nurturing while performing the task (Travis). This protective behavior can also be referred to as ownership. When the job is done well, the 
employee feels good about their accomplishment and themselves. When an employee loses interest in doing a great job, the value of an intrinsic reward system is lost. The probability of job burnout is much greater when employees do not care about the outcome of their work (Angerer, 2003). Extrinsic and intrinsic rewards are both positive factors that increase an employee's job satisfaction and lessen the probability of job burnout. Rewards, extrinsic and intrinsic, are both related to job satisfaction (Huang \& Vliert, 2003). External rewards, such as pay and job security, are contingent upon a supervisor deeming that the employee's work is worthy of recognition and therefore is not guaranteed. It is vitally important that an employee feel good about their work, and is able to self-motivate until the extrinsic rewards are given by management.

\section{JOB BURNOUT AND COMMUNITY}

A successful team creates a community environment that fosters support, laughter, comfort, praise and respect (Angerer, 2003; Maslach et al., 2001). The breakdown of community in the workplace causes a decline in teamwork. Cauce (2007) stated that a sense of community is established when employees form relationships. An environment that fosters collaborative partnerships reduces stress and increases the overall productivity of a team.

According to Burroughs and Eby (1998), the definition of community has four elements: membership, influence, integration, and fulfillment of needs and shared emotional connection. Royal and Rossi (1996) reported that membership "is a feeling of belonging or of sharing a sense of personal relatedness" (p. 400). When an individual feels that they are part of the team, a sense of community is established. They feel valued and therefore feel connected to their coworkers. Influence is defined as "a sense of mattering and of making a difference to a group and the group matters to its members" (Burroughs \& Eby, p. 511). Having a voice is an important component of community. Working with others in the decision making process involves, participation, teamwork and communication. People feel a sense of community when they have an opportunity to influence the direction of the group.

The third element of community is the integration and fulfillment of needs, which involves the ability of the group to motivate team members to participate in the group (Burroughs \& Eby, 1998; Royal \& Rossi, 1996). Royal and Rossi recognized caring, respect and recognition as motivating factors for group participants. Again, being empathetic, respecting the individual and their ideas and recognizing achievements are lend to creating a sense of community. The final element is shared emotional connection, which is defined as a belief that members have shared and will share a history, common places, time together and similar experiences (Burroughs \& Eby; Royal \& Rossi). When employees feel that they share a common value system, the level of trust increases and a stronger sense of community is born.

Burroughs and Eby (1998) reported that employees with a sense of community are aware that the sense of community provides creative expression that allows the organization to be productive. These individuals see the organization as a part of their family and not simply a place to receive a paycheck. They are emotionally invested in the success of the organization and their coworkers. Burroughs and Eby stated that organizations can create this type of community environment by allocating promotions fairly, providing jobs that are challenging, encouraging interaction among workers and not overwhelming workers with job responsibilities.

Maslach et al. (2001) stated that a mismatch occurs when there is not a positive connection between people in the workplace. Angerer (2003) supported this argument for mismatch, stating that the mismatch happens because of decreased job security and the transient nature of employment. In the past, the idea that an employee would graduate from high school and work at a company until retirement created a sense of community because relationships were able to grow over a period of time. However, in today's modern job market, employees may be terminated or choose to leave for a job that offers an increased salary or higher position. The emotional bonds in today's work environment are harder to establish because of the constant coming and going of employees.

An established workplace community is beneficial for the overall organization as well as individuals. The strength of the community invigorates individuals and creates a sense of pride, respect and support. All of these components increase job satisfaction and loyalty, and decrease the probability of job burnout. 


\section{JOB BURNOUT AND FAIRNESS}

When employees perceive that the workplace uses unfair tactics, morale drops, loyalty vanishes, and the cycle of job burnout begins. According to Maslach et al. (2001), fairness confirms the employee's self-worth and increases respect. Lack of fairness is displayed when there is inequity in workload or pay, cheating, or promotions/evaluations are not handled appropriately (Angerer, 2003; Maslach et al.). The end result of workplace inequity is cynicism, exhaustion and emotional turmoil. Angerer stated that there are three elements to a fair workplace: trust, openness, and respect. When an organization establishes a trusting environment, shows respect for all employees and is open about their intentions, its employees feel a sense of community.

Messer and White (2006) reported that employees who believe that they have received fair treatment will have positive attitudes about their work and supervisors. Conversely, employees who believe they have been treated unfairly will have negative attitudes about their work environment (Angerer, 2003). Also, when employees believe they have not received fair treatment, they may hold back on job responsibilities and work output (Messer \& White). McIntyre, Bartle, Landis, and Dansby (2002) stated that perceived fairness in the workplace has an impact on job satisfaction and commitment. The absence of unfair treatment in the workplace will foster a stronger team and reduce job burnout.

\section{JOB BURNOUT AND VALUES}

Maslach et al. (2001) stated that value mismatch occurs when there is a conflict between the employee's values and the company's value system, or when there is a discrepancy between the company's mission statement and the actual practices of the organization. Seigall and McDonald (2004) reported that negative outcomes occur when there is a lack of congruence between the employees and organization's value system. When the employee is conflicted because of competing value systems, stress will manifest and cause the employee to exhibit signs of burnout. Bouckenooghe, Buelens, Fontaine, and Vanderheyden (2005) reported that there has been a limited amount of research conducted to measure stress and conflicting values. Of the six domains of job burnout established by Maslach et al., the value domain of job burnout has received minimal research. Maslach et al. stated that if there is a mismatch in this domain, "people might feel constrained by the job to do things that are unethical and not in accord with their own values" (p. 415). Having to bend the truth or mislead individuals for the good of the company can cause significant stress on employees. Emotional exhaustion may occur if employees are chronically exposed to value conflict. Bouckenooghe et al. stated that it is vitally important to establish a link between value conflicts and stress. Currently, there is a limited amount of empirical research on job stress and value conflict. However, the studies that have been conducted show that value congruence leads to greater job satisfaction, stress reduction and reduces job burnout (Bouckenooghe et al.).

The new framework established by Maslach et al. (2001) addresses the employee's contribution as well as the organization's contribution to job burnout. The domains of workload, control, reward, community, fairness, and values provide a conceptual framework to understand job burnout (Maslach et al.). In addition to a deeper understanding of job burnout, the new framework emphasizes viewing the person in the context of the work environment versus seeing the two as separate, never-intersecting factors. Angerer (2003) stated that organizations must address each of these six domains to effectively extinguish burnout. The benefits to addressing each domain are enthusiastic, loyal, and effective employees who have a greater focus on customer satisfaction. However, organizations that do not address the domains will drive employees towards symptoms of burnout such as exhaustion, depersonalization, and reduced efficacy.

Two surveys, Areas of Work Life Survey and the Maslach Burnout Inventory-General Survey, were used to determine the relationship between burnout and areas of work life.

The Areas of Work Life Survey (AWS) was designed by Michael Leiter and Christina Maslach and the Center for Organizational Research and Development to evaluate six areas of the context of work life: workload, control, reward, community, fairness, and values. This survey was designed to offer practical and economic measurement of work factors so that the antecedents of job burnout can be identified (Maslach, Jackson \& Leiter, 1996). Once the 
factors have been identified, organizations can then move towards creating preventative policies to reduce the possibility of job burnout.

The survey consists of 29 items that cover work life areas. The items are worded as statements of perceived congruence or incongruence between oneself and the job. The survey includes positively worded items of congruence (e.g., "I have enough time to do what's important in my job") and negatively worded items of incongruence (e.g., "Working here forces me to compromise my values"). Respondents indicate their degree of agreement with these statements on a 5-point Likert-type scale ranging from 1 (strongly disagree), through 3 (hard to decide), to 5 (strongly agree). The scoring for the negatively worded items was reversed.

For each of the six subscales, the AWS defines congruence as a high score (>3.00), indicating a higher degree of perceived alignment between the workplace and the respondent's preferences. Conversely, it defines incongruence as a low score $(<3.00)$, indicating perceived misalignment or misfit between the worker and the workplace.

As a first stage of the analysis, I determined the reliability of each subscale, as measured by Cronbach's alpha. As with the MBI-GS scales, all AWS scales were highly reliable, with alpha above .80 . The means for each scale suggest that there is high degree of perceived alignment between the workplace and the respondent's preferences (average score greater than 3) in all but one area. Specifically, nursing home administrators appear to exhibit incongruence (score lower than 3.00) in the workload area, indicating perceived misalignment or misfit between the worker and the workplace in terms of amount of work. The area that respondents are most satisfied with concerns the alignment of values between respondents and their organizations $(M=4.77, S D=.65)$.

\section{DISCUSSION}

\section{Research Question}

The research question asked to what extent each independent variable (workload, control, rewards, community, fairness, and values) predicts job burnout for the nursing home administrator?

Nursing home administrators in Georgia reported a strong congruence between their values and their organizations values. This sense of being on the same page allows an administrator to have confidence in the organization's mission. Believing in the organization's mission is highly valuable to any employee. The importance is magnified for an employee in a stressful environment.

It is important to discuss the most important correlates for each of the three burnout components. For instance, the most important factors that appear to cause feelings of exhaustion for nursing home administrators are workload $(r=$ -27) and community $(r=-27)$. Although the first result was to be expected, the link between community and exhaustion is less intuitive and suggests that the inadequate relationship with colleagues and lack collaboration at work can lead to exhaustion.

Second, cynicism appear to be affected most by control $(r=-31)$ and community

$(r=-.31)$ areas. The first correlation suggests that a perceived lack of autonomy contributes more than a heavy workload to the administrator's feelings of cynicism. The second correlation demonstrates the importance of a healthy community at work in reducing cynicism. Third, professional efficacy seems be influenced most by control $(r=.28)$ and fairness $(r=.26)$. It is interesting to note that professional efficacy was not associated with workload.

Lastly, it is important to note some surprising nonsignificant findings. One would have expected that burnout would be related to number of hours worked and number of years of experience as a nursing home administrator. Neither of these variables was found to be significantly related to burnout. Another surprising result was that the area of values was not correlated to any of the three burnout components. This might be due to the relatively low variance in the values score $(S D=.65)$, and the fact that the large majority of respondents pointed to high congruence between their values and their organization's values. This finding is encouraging nevertheless, because emotional exhaustion may occur if employees are chronically exposed to value conflict. 


\section{CONCLUSION}

Among the areas of work life, community was the most important predictor of job burnout. This result suggests that improving the quality of collegial relationships might be an effective target of preventive intervention. Nursing home administrators who can be identified as already at risk for burnout may be having difficulties in their relationships with their colleagues, and so community interventions might be important for this particular group. The study implies that the quality of collegial relationships could be an important marker when assessing burnout among nursing home administrators.

Given the current workforce shortage in nursing homes, every effort must be made to ensure that administrators are exposed to high quality work environments that engage them with their work and reduce their levels of emotional exhaustion. The results of the study further highlight the need to ensure that nursing home environments foster good quality and collegial working relationships, to guarantee that highly skilled administrators remain engaged in their work. In addition, the importance of control in predicting burnout underscores the need to give sufficient autonomy to nursing home administrators in managing resources.

\section{AUTHOR INFORMAITON}

Felicia Odum Wilson is a licensed master social worker and licensed nursing home administrator in the State of Georgia. Dr. Wilson earned a doctoral degree from Capella University, master of social work degree from Florida State University and bachelor of social work degree from Alabama State University. Dr.Wilson's research is twofold: workplace stressors for human service professionals and treatment options for geriatric depression. She is currently employed by Saint Leo University as an associate professor of human services. E-mail: felicia.wilson@saintleo.edu

\section{REFERENCES}

Angerer, J. M. (2003). Job burnout. Journal of Employment Counseling, 40(3), 98-107.

Bouckenooghe, D., Buelens, M., Fontaine, J., \& Vanderheyden, K. (2005). The prediction of stress by values and value conflict. The Journal of Psychology, 139(4), 369-382.

Burroughs, S. M., \& Eby, L. T. (1998). Psychological sense of community at work: A measurement system and explanatory framework. Journal of Community Psychology, 26(6), 509-532.

Cauce, A. M. (2007). Bringing community psychology home: The leadership, community and values initiative. American Journal of Community Psychology, 39(1), 1-11.

Cavanaugh, J. C., \& Blanchard-Fields, F. (2002). Adult development and aging (4th ed.). Pacific Grove, CA: Wadsworth/Thomson Learning.

Cherniss, C. (1980). Staff burnout: Job stress in the human services. Beverly Hills, CA: Sage.

Cordes, C. L., \& Dougherty, T. W. (1993). A review and an integration of research on job burnout. Academy of Management Review, 18(4), 621-656.

Crampton, S. M., Hodge, J. W., Mishra, J., \& Price, S. (1995). Stress and stress management. SAM Advanced Management Journal, 60(3), 1-11.

Eft-Russ, D. (2001). Workload, stress, and human resource development. Human Resource Development Quarterly, 12(1), 1-3.

Greenglass, E. R., Burke, R. J., \& Moore, K. A. (2003). Reactions to increased workload: Effects on professional efficacy of nurses. Applied Psychology: An International Review, 52(4), 580-597.

Huang, S., \& Vliert, E. V. (2003). Where intrinsic job satisfaction fails to work: National moderators of intrinsic motivation. Journal of Organizational Behavior, 24(2), 159-179.

Khodyakov, D. M. (2007). The complexity of trust-control relationships in creative organizations: Insights from a qualitative analysis of a conductorless orchestra. Social Forces, 86(1), 1-22.

Maslach, C., Jackson, S. E., \& Leiter, M. P. (1996). The Maslach Burnout Inventory (MBI) manual (3rd ed). Palo Alto, CA: Consulting Psychology Press.

Maslach, C., Schaufeli, W. B., \& Leiter, M. P. (2001). Job burnout. Annual Review of Psychology, 52 (1), $397-422$.

McIntyre, R. M., Bartle, S. A., Landis, D., \& Dansby, M. R. (2002). The effects of equal opportunity: Fairness attitudes on job satisfaction, organizational commitment, and perceived work group efficacy. Military Psychology, 14(4), $299-319$.

Messer, B. A. E., \& White, F. A. (2006). Employees' mood, perceptions of fairness, and organizational citizenship behavior. Journal of Business and Psychology, 21(2), 65-82.

Parry-Jones, B., Grant, G., McGrath, M., Caldock, K., Ramcharan, P., \& Robinson, C. (1998). Stress and job satisfaction among social workers, community nurses and community psychiatric nurses: Implications for the care management model. 
Health and Social Care in the Community, 6(4), 271-285.

Royal, M. A., \& Rossi, R. J. (1996). Individual-level correlates of sense of community: Findings from workplace and school. Journal of Community Psychology, 24(4), 395-416.

Seigall, M., \& McDonald, T. (2004). Person-organization value congruence, burnout and diversion of resources. Personnel Review, 33(3), 291-301.

Tai, W. T. (2007). An investigation of the influences of job autonomy and neuroticism on job stressor-strain relations. Social Behavior and Personality, 35(8), 1007-1019.

Templeton, M. C., \& Satcher, J. (2007). Job burnout among public rehabilitation counselors. Journal of Applied Rehabilitation Counseling, 38(1), 39-45.

Travis, D. (2006). Is doing good enough? A path analytic model of intrinsic job satisfaction among human service workers. Journal of Workplace Behavioral Health, 22(1), 13-32. 